\title{
EFFECTIVE PRACTICES IN FACILITATING NONTRADITIONAL ADULT LEARNERS' DISSERTATION WRITING IN AN ONLINE DOCTORAL PROGRAM
}

\author{
Mei Jiang, Texas A\&M University-Commerce (TX) \\ Melissa Arrambide, Texas A\&M University-Commerce (TX) \\ Ava Munoz, Texas A\&M University-Commerce (TX)
}

\begin{abstract}
To address the challenges nontraditional adult doctoral learners face in completing dissertations online, we reflect on the effective practices utilized in an online doctoral-level educational leadership program at a public university in the United States. This paper focused on two major topics: 1) how to prepare students to write a dissertation through coursework based on the Competency-based Education (CBE) theory; and 2) how to build relationships between mentors and students writing dissertations based on the Community of Inquiry (CoI) framework. The theoretically founded practices based on CBE and CoI must be utilized in building an interactive, collaborative online learning community.
\end{abstract}

Keywords: competency-based education, dissertation writing, online learning

\section{INTRODUCTION}

According to the andragogy theory (Knowles, 1970, 1985), adults' learning is self-directed and intrinsically motivated, and adults are eager to understand the rationale behind learning. As a major theoretical framework of adult education, the andragogy learning theory highly values adult learners' life experiences and believes it is learners' prior experiences that provide a foundation for their learning. Also, adult learners normally have immediate needs to apply their learning to fulfill their social roles and to solve practical problems (Holton et al., 2001). In the higher education programs serving nontraditional adult learners, it is imperative that adult learners' learning characteristics are well understood so that appropriate and effective andragogical educational practices can be provided in teaching and mentoring. This becomes especially challenging when learning takes place online, where face-toface interaction is absent.

In recent years, the way education is delivered has transformed dramatically with the increasing popularity of internet and digital technologies (e.g., email, instant messaging, Interactive video conferencing, mobile/smartphones, and social networks) (Cook \& Sonnenberg, 2014; Friedman \& Moody, 2021). With the exponential growth of online technology usages and activities, there has been a rapid growth in online course enrollment in higher education. Data from the Babson Survey Research Group showed that more than 6.3 million students in the United States took at least one online course in fall 2016 (Seaman et al., 2018). U.S. public colleges and universities had a 7.3\% increase in online course enrollment between fall 2015 and fall 2016, and private nonprofit schools had an increase of $7.1 \%$. In the state of Texas, among 53 doctoral-level educational leadership programs at public universities, $40(75.4 \%)$ are either $100 \%$ online, fully online $(86 \%-99 \%)$, or hybrid/blended/ electronic (Texas Higher Education Coordinating Board, 2018).

For many doctoral programs in higher education, one of the challenges they face is that many students end up at the all-but-dissertation (ABD) stage, 
leading to attrition issues. According to the Council of Graduate Schools (2017), approximately $50 \%$ of doctoral students fail to complete their terminal degrees. Online doctoral students have been shown to have a higher risk of degree noncompletion than their counterparts in traditional programs (Cross, 2014; Ehrenberg et al., 2009; Johnson et al., 2000; Terrell et al., 2016). One major obstacle has been the transition from coursework to writing and completing the dissertation (Fiore et al., 2019). The Council of Graduate Schools (1977, cited in Bargar \& Duncan, 1982) defined the main purpose of doctoral training as being "to prepare a student for a lifetime of intellectual inquiry that manifests itself in creative scholarship and research" ( $p$. 1). In theory, the dissertation offers the training that enables students to transition from "student" to "independent scholar," but in reality, it has remained a major challenge for doctoral programs to find the best way to foster students' transitions to becoming independent researchers (Lovitts, 2008). Faculty need training, external supports, and prolonged experience in developing online teaching skills in mentoring dissertation research (Mcgee et al., 2017) because hardship and ambiguity have been commonly reported surrounding the dissertation process from the student perspective (Gardner, 2010).

Given the characteristics of nontraditional adult learners and the challenges online learners face in completing dissertations, this paper was written from the dissertation chair/faculty perspective and reflects on effective practices thatcould help facilitate nontraditional students' dissertation writing in an online program. The program examined in this paper is a $100 \%$ online educational leadership doctoral program at a doctorate-granting, public university in Texas. All students in this program are nontraditional adult learners who hold full-time leadership positions in $\mathrm{K}-12$ educational systems in Texas while enrolled in the program. Benefiting from the flexibility of learning without geographic and temporal limitations, students are able to take courses and complete their dissertations online in either a synchronous or asynchronous manner. With a high enrollment of approximately 300 doctoral students, both faculty and students face challenges in dissertation writing/mentoring and in improving students' terminal degree completion rate. We focused on the following questions: 1) How can we prepare students for their dissertation research through the courses we teach? Particularly, how can we enhance the instructional effectiveness of research methods courses? 2) What are the relationship-building practices that could help improve dissertation mentoring effectiveness in working with doctoral students online?

It is our hope that the practices discussed in this paper will reveal options that could be implemented to facilitate online, nontraditional adult doctoral learners' dissertation writing in higher education. We discuss two theoretical frameworks below to lay the theoretical foundations, followed by descriptions of best practices that are theoretically based yet pragmatic. Through reflecting on the practices used in our daily online teaching job, we hope to inspire more discussion about how to support nontraditional doctoral learners' dissertation writing in the online learning environment.

\section{THEORETICAL FRAMEWORKS}

\section{Competency-Based Education (CBE)}

According to Competency-Based Education (CBE), in designing educational courses or programs, students' learning outcomes are established first, instructional pedagogy is aligned with the learning outcomes in the design process, student success is measured with a structured methodology, and curriculum adjustments are made after the outcomes are evaluated (Gervais, 2016; Le et al., 2014; Priest et al., 2012; Spady, 1977). Johnstone and Soares (2014) proposed five principles for successful CBE model implementation: (1) the degree reflects robust and valid competencies; (2) students are able to learn at a variable pace and are supported in learning; (3) effective learning resources are available anytime and are reusable; (4) the process for mapping competencies to courses, learning outcomes, and assessments is explicit; and (5) assessments are secure and reliable. It is believed that with successful implementation of those five principles, $\mathrm{CBE}$ could succeed in enhancing students' knowledge mastery and skills application in the real world. Rivenbark and Jacobson (2014) further noted that a successful mission-based CBE program should be well-balanced between theoretical, conceptual knowledge and practical skill acquisition. Well- 
designed competencies should increase skills without sacrificing academic rigor.

In fostering doctoral learners' dissertation writing, a strong collaborative community is the key (Peters et al., 2015). From the whole-system design perspective, they pointed out that a series of components should be included in a program to meet the anticipated competencies of the program. Peters et al. utilized multiple strategies to help with the "abrupt" transition from coursework to dissertation writing in the early dissertation writing process. For example, weekly collaborations between faculty and students were utilized to establish a collaborative learning community where mutually agreed upon goals were reached to advance the dissertation; weekly peer meetings were arranged for students to share ideas and concerns with one another to create a safe space in the collaborative community; and additional structured partnerships between faculty and students were established to allow faculty to share personal experiences to provide psychological support for doctoral students in dealing with anxiety and feelings of abruptness and unsettledness. Another important piece of the collaborative community was the role methodologists play in dissertation writing (Peters et al., 2015). Methodologists were proactively integrated into the program as full dissertation partners. Instead of functioning as an "enhancement or add-on," methodologists played a fundamental role in helping students connect dissertation research questions with appropriate research tools. All components in this program were well-aligned with the CBE rationale in building an effective, collaborative community to foster students' dissertation writing.

\section{Community of Inquiry (CoI)}

The Community of Inquiry (CoI) framework (Garrison et al., 2000) is one of the major theories about how to structure the learning process in an online environment. In the CoI framework, three elements are interrelated: cognitive presence, teaching presence, and social presence. Cognitive presence is "the extent to which learners are able to construct and confirm meaning through sustained reflection and discourse" (Garrison et al., 2001, p. 11). Teaching presence is "the design, facilitation, and direction of cognitive and social processes for the purpose of realizing personally meaningful and educationally worthwhile learning outcomes (p. 5). Social presence was defined as "the ability of participants to identify with the community, communicate purposefully in a trusting environment, and develop interpersonal relationships by way of projecting their individual personalities" (Garrison, 2009, p. 352). Lipman (2003) posited that CoI is "thoroughly social and communal, a method for integrating emotive experience, mental acts, thinking skills, and informal fallacies into a concerted approach to the improvement of reasoning and judgement" ( $p$. 18). Cleveland-Innes and Campbell (2012) further emphasized emotive experience in online learning and defined emotional presence as "the outward expression of emotion, affect, and feeling by individuals and among individuals in a community of inquiry, as they relate to and interact with the learning technology, course content, students, and the instructor" (p. 283). For midcareer adult online learners, social support from family, friends, and peers was found to be predictive of their academic self-regulation (Williams et al., 2019).

While it is important to incorporate cognitive, learning, and social presences in online programs, the role emotion plays in the daily instructional practices should be highlighted in online teaching and mentoring. Emotional presence and relationship building are essential for building a successful online learning community to create a safe environment for students to learn. For example, a cohort experience and a face-to-face orientation were found to be critical to the sense of community among online doctoral students (Byrd, 2016). In a one-to-one online math coaching program using text-based chat and a shared digital whiteboard, emotional presence was found to be essential and distinctive in students' learning process (Stenbom, Hrastinski, \& Cleveland-Innes, 2016). In another online assignment where students read, researched, and viewed videos about the homeless population, students' emotional responses were found to be fundamental to their deep learning and lasting knowledge acquisition (Williams, 2017). It was noted that emotions encountered in completing this assignment connected students, particularly adult students, to their real-life experiences. Williams recommended authentic learning design, generalizability, and experiential 
teaching for incorporating emotional presence into online course design.

\section{PRACTICE ONE: PREPARING STUDENTS FOR DISSERTATION IN COURSEWORK}

While doctoral learners' transition to dissertation writing could be fostered through a collaborative mentoring process at the early dissertation stage as discussed above (Peters et al., 2015), we believe it is important to equip students with the competencies needed for the dissertation during the coursework stage. Given such, it becomes critical to utilize $\mathrm{CBE}$ rationales in our fully online doctoral program to identify and incorporate the essential knowledge and skills into the program/course design. Aligned with the CBE rationale, the first practice discussed here uses an online statistics course design as an example to show how to prepare online adult learners during the coursework stage.

Past research has questioned the effectiveness of online statistics teaching due to the abstract nature of this subject (Larwin \& Larwin, 2011; Lu \& Lemonde, 2013). It was claimed that online statistics teaching barely produced comparable learning outcomes to those of face-to-face teaching, especially among lower-performing students. In this situation, it becomes the central focus of doctoral programs to offer quality online statistics courses where students can learn and acquire the expected dissertation competency. The sequence of course content, communication modes, and assignment structures should be considered (Baldwin, 2017), and effective instructional strategies (e.g., curriculum and instructional styles and pedagogical means) should be incorporated into the design to guide the development of course content, student engagement, and learning activities (Bonk \& Dennen, 2003). Instruction regarding reflection should also be incorporated into the course design to enhance the breadth and depth of higher order learning in a blended course (McDonald et al., 2014).

In the online, doctoral-level educational leadership program discussed in this paper, the online, doctoral-level introductory statistics course covers fundamental statistical concepts and focuses on the application of statistical tests in research. The course's ultimate goals are that students gain fundamental statistics knowledge, understand quantitative research design, and, most importantly, apply their knowledge base to actual data analysis for their dissertation. After identifying such an anticipated competency for students' dissertation writing, the instructor laid out the specific knowledge and skills the students were expected to master for their dissertation writing, which included basic concepts about quantitative research design and variables, descriptive statistics, correlation and simple regression, independent samples t-test, dependent samples t-test, one-way ANOVA with post hoc test, and chi-square. IBM SPSS software was also utilized in this course so the students could acquire practical skills for their dissertation research. Each course module was then carefully designed to ensure that the students acquired the knowledge mastery and skills regarding the concepts identified above. Each unit included three components (i.e., study materials, quiz, and miniproject assignment), and students were required to complete each in order. Under study materials, multiple lectures on PowerPoint were presented in 5- to 15-minute short videos to cover various topics. Lectures on big topics were broken down into a series of shorter episodes to ensure that the lectures could fit into nontraditional students' schedules. In each module, quizzes were used to enhance the students' conceptual learning of statistics, and miniproject assignments were used to develop the students' datarelated skills using IBM SPSS. Meanwhile, optional weekly synchronous Q\&A sessions were conducted via Zoom to provide "face-to-face" communication for clarification, feedback, or lectures in the hope of enhancing immediacy by building a sense of an online learning community (Tsai, et al., 2008; Williams, 2010).

In a qualitative study, 15 students were asked to answer five open-ended reflection questions (Yang, 2017) about how they perceived the effectiveness of the instructional strategies and course design features of this course (Jiang et al., 2019). The five reflection questions were:

1. What was the most effective instructional strategy (such as PowerPoint with lectures, documents, miniproject assignments, weekly Q\&A sessions) that helped you learn?

2. How do you perceive the instructional strategies adopted or the course design in this online course? 
3. Were there any other instructional strategies that were not adopted in this course that you used on your own?

4. Were the learning activities helpful for you to learn the concepts/materials? What kind of activity (activities) did you find the most helpful?

5. Do you have any other comments for the course? Please be specific.

Content analysis revealed that students preferred PowerPoint presentations with lecture recordings and synchronous Q\&A sessions. More importantly, students valued the cohesiveness of the course design and the umbrella design encompassing PowerPoint, Q\&A sessions, supplemental documents, the miniproject assignment, and quizzes. All strategies were perceived by students to be closely related and to build their data analysis skills. For example, a student stated that they liked how the course design "was the spiraling of concepts from one lesson to the next. We continued to use the terminology and strategies week to week. Each week in IBM SPSS built upon a previous week." When asked to reflect on their learning experiences, students said they enjoyed the opportunity to play around with real data in their coursework. While learning theory is the cornerstone of learning, $\mathrm{CBE}$ could help bridge the gap between academics and working fields by transforming knowledge into concrete skills that learners need to master and implement in the real world. A student shared,

The learning activities were especially helpful. The assignments that we completed each week helped me to apply the concepts. The practice with the IBM SPSS program was very beneficial and actually enjoyable. When I completed a weekly assignment, I felt a great sense of accomplishment and understanding. Although I am not sure I recognize every time I should use a particular test, I am much more confident than I was when I began this course.

It is evident that students gained self-efficacy and became more confident in using the skills they learned in this course for future work. Students' feedback about this CBE-oriented course design makes us realize that adult learners heartily value the direct impact of classroom learning when the course design empowers them to apply what they learn to solving real-world problems (Holton et al., 2001). A student simply pointed out that we need to "work on the dissertation throughout the online courses."

Based on the practice used in this online statistics course in the doctoral-level educational leadership program discussed in this paper, our belief is that a competency-based course design could be the key starting point in preparing students for the transition to independent research. In a course where modules are built upon the anticipated competencies required for students' future projects and where course learning activities are wellaligned with the needed outcomes, students will be more likely to move towards their dissertation writing goals with confidence. In this case, the capability and confidence students built from the coursework could be readily transferred to their dissertation writing, making them less likely to get intimidated by their dissertation research projects (Johnstone \& Soares, 2014).

\section{PRACTICE TWO: RELATIONSHIP BUILDING IN DISSERTATION WRITING}

Past research on the CoI framework suggested the importance of the emotional component in online learning (Cleveland-Innes \& Campbell, 2012; Stenbom, Hrastinski, \& Cleveland-Innes, 2016; William, 2017) and age was found to be significant to online learning (Akyol et al., 2010; Shea \& Bidjerano, 2009). In this paper, we would like to further argue that, given the characteristics of online, nontraditional adult learners, more attention should be paid to emotional presence and relationship building in mentoring learners in dissertation writing. Since older learners may have a different perception of learning because of their prior work and life experiences, andragogical strategies should be reconsidered to help nontraditional adult learners with the dissertation.

There are many different approaches to writing a dissertation and no one approach is necessarily better than another. This holds especially true for nontraditional adult learners who work full time in a leadership position in $\mathrm{K}-12$. Learners in our doctoral program all present with different backgrounds, learning styles, capacities, and skill sets. For students with a clear dissertation idea in mind, the chair's standard guidance quickly 
leads them to identify the problem and lay out the methodological details of the study, but for others with only remotely appropriate research ideas, more effort is needed from both the student and the mentor. Students' intrinsic motivation for taking the initiative in this case sets successful learners apart from their counterparts (Joyner, et al., 2018). Students' successful dissertation completion is highly contingent on and affected by an individual student's competence and dedication to the process. Learners who possess excellent writing and communication skills are usually the best at taking direction from their chairs and making suggested revisions throughout the dissertation process; those who do not choose to take direction from the chair are the ones who make the process the most difficult.

In this online doctoral program, students hold school leadership positions, and at times may be more resistant to taking instructional directives from mentors. It is worth noting that students' emotional states could get in their way during the dissertation writing stage. Learners sometimes feel frustrated, exhausted, and angered by their slow progress. It is not uncommon for chairs to work with learners who may no longer be willing to listen or grasp their advisor's words of wisdom. The quality of the dissertation becomes less of concern to such students than reaching the finish line.

The experiences and observations mentioned above led us to one key question: What are the best practices that could help students make progress with the dissertation? In the online statistics course discussed above, synchronous communication via Zoom conferencing created a welcoming tone for the students and personalized their online learning experiences. Similarly, relationship building was found to be a critical component in dissertation writing (Jiang \& Koo, 2020). In a qualitative study, 35 doctoral students in the online educational leadership program were asked three openended questions regarding their online learning experiences: Question 1 asked about students' overall online learning experiences and whether they were satisfied and why, question 2 asked about the challenges students faced in their online learning, and question 3 focused on what they needed for a better online learning experience.

Students' responses showed their recognition and appreciation of the connection they had with their instructor and peers. One student stated, "I am grateful for my advisor [who] also served as my dissertation chair. Dr. A was always responsive, answered emails promptly and did not hesitate to call me when necessary. Three reasons: convenience, responsive professors, clear expectations." Such a statement indicates that students need a close connection with their chair and it highlights the importance of relationship building in creating a collaborative online learning community. When asked about the challenges they faced in online learning/mentoring, some students showed their disappointment due to a lack of connection or sense of belonging to the program. They conveyed strong messages about the need to get connected to their chair and peers for either educational resources or simply for psychological support. For example, a student suggested "more face to face interaction" and a "once a year meet and greet" with faculty: "A schedule of expected communication between professor and student . . . at a minimum of monthly [meetings]." More than that, students expressed their need for more connection with the program and the university as a whole. Some wanted "more interaction with fellow classmates" and expressed a need to "connect students to other university information and discussions." On-site connections were noted by quite a few students: "Meeting professors and other students in person or have a set day for a video conference for part of the learning."

From the students' responses above, we determined that there is a great need to get students and advisors connected and working in collaboration through different venues, including asynchronous and synchronous online communication. From the mentor perspective, it was evident that a strong learner-chair relationship is the key that would keep the learner-chair connection open to guarantee effective and efficient communication in facilitating dissertation work. No matter whether it is in-person, face-to-face communication, video conferencing, or telephonic interaction, the keys are to make connections, build a relationship, and keep communication open so learners feel safe and confident in their dissertation writing (Smith et al., 2017). The learner and the chair must function as two individuals in a "collaborative relationship who aim to resolve an educational issue" (Stenbom, 
Jansson, \& Hulkko, 2016, p. 38). In addition to providing expectations and guidelines revolving around appropriate engagement and participation to enhance students' comfort "in exchanging constructive, collegial ideas with others" (Reio \& Crim, 2013, p. 31), a relationship of inquiry should be established between an advisor and advisee when face-to-face communication is lacking in the online learning environment (Stenbom, Hrastinski, \& Cleveland-Innes, 2016). Relationship building is the key in creating an authentic learning experiences for online learners.

\section{DISCUSSIONS AND IMPLICATIONS}

While the dissertation writing process is certainly not new, the mode by which online learners complete the process has taken on a new blueprint. The research-based best practices presented above show great potential to provide effective online teaching and mentoring practices in working with nontraditional students in higher education. To facilitate the work of nontraditional, online dissertation students, our first thought is to apply CBE theory in creating a doctoral program that prepares students for the dissertation challenge. The pedagogical strategies that should be focused on in course design first include establishing anticipated learning outcomes, aligning instructional pedagogy with the identified competencies and skills, and making curriculum and instruction adjustments based upon student feedback. It is critical to map the anticipated competencies to the course learning outcomes to ensure course design success through objective assessments (Gyll \& Ragland, 2018; Nodine, 2016). Furthermore, it is important to make students aware of the course alignment so they understand that the knowledge and skills learned in the course are applicable in the real world so that students' learning interest, self-efficacy, and learning effectiveness can be enhanced.

Secondly, building relationship with students is the key starting point in working with them in the online learning environment. Reflecting on the practices used in teaching and mentoring dissertation students, and the feedback collected from students, we believe emotional, psychological support could be the magic missing piece to online learning and mentoring. On top of the teaching, cognitive, and social presence elements of the CoI framework (Garrison et al., 2000), it was evident how critical the emotional component is in the dissertation process. As Cleveland-Innes and Campbell (2012) proposed, the exchange of emotion, affect, and feeling between the chair and the student may be indispensable to the success of dissertation mentoring online. In the online learning environment, psychological support should be the first issue addressed before proceeding to the dissertation work per se. Given that, individualized, one-on-one chair-student interaction should be provided to address the challenges nontraditional dissertation students face in the online setting.

There are several specific practices that can be beneficial to nontraditional online dissertation students:

1. In the proposal writing stage, respect students' different learning styles to meet their individualized needs. Some students prefer meeting face-to-face while others are comfortable with receiving written feedback. Chairs should do their best to meet individualized student needs and embrace different learning styles.

2. Regardless of the format of the communication, focus on establishing a great sense of trust, flexibility, and belongingness in the learner-chair relationship.

3. In the data collection stage, keep the communication channel open so that strongwilled students can be directed to follow the proposed design without deviation and conduct research within the ethical parameters.

4. In the post-data collection stage, make sure to continue weekly communication via phone, online, and in person. Learnerchair interactions and the frequency of those interactions normally are the deciding factors in students' completion of the dissertation process.

5. Build a supportive community where students are wholly supported by strong, nurturing committee members. We must understand that the dissertation is vastly unpredictable, unparalleled in rigor, and contingent on many factors. Therefore, it is 
important to establish a good, coherent bond among the learner, chair, and committee members.

6. Focus on the long-term student-chair relationship. Students who establish strong bonds with their chairs are more likely to successfully complete their dissertations. Sometimes a close relationship with the chair postgraduation enables them to pursue a teaching job in higher education.

\section{CONCLUSIONS}

The move from face-to-face classroom instruction to online instruction has changed teaching and how students learn. To ensure nontraditional students' preparedness for the dissertation and future challenges, we must embrace the theoretically founded practices put before us that have been shown to be successful and use CBE for structuring an effective program. Additionally, CoI guidance must be utilized when building an interactive, collaborative learning community in an online learning environment. By sharing the time-tested strategies that we have utilized in the process of leading learners through the dissertation, it is our hope to shed light on ways to enhance online educators' teaching and mentoring competencies in higher education.

\section{LIMITATIONS AND FUTURE RESEARCH}

This paper focused on nontraditional adult dissertation students in the educational field; therefore, the discussion and conclusions might be limited in their implications for other majors and populations in higher education. Future studies could examine different student bodies, such as those who learn in different settings with different cultures (i.e., low SES, rural, or marginalized populations), regardless of being traditional or nontraditional. After all, taking advantage of technology and the internet and finding ways to maximize their advantages for educational purposes should be goals for all educators. 


\section{REFERENCES}

Akyol, Z., Ice, P., Garrison, R., \& Mitchell, R. (2010). The relationship between course socio-epistemological orientations and student perceptions of community of inquiry. The Internet and Higher Education, 13(1-2), 66-68. https://doi. org/10.1016/j.iheduc.2009.12.002

Baldwin, S. J. (2017). Adaptation and acceptance in online course design from four-year college and university instructors: an analysis using grounded theory [Doctoral dissertation, Boise State University]. http://scholarworks.boisestate.edu/td/1241

Bargar, R. R., \& Duncan, J. K. (1982). Cultivating creative endeavor in doctoral research. Journal of Higher Education, 52(1), 1-31. https://doi.org/10.2307/1981536

Bonk, C. J., \& Dennen, V. P. (2003). Frameworks for research design, benchmarks, training and pedagogy in web-based distance education. In M. G. Moore \& W. G. Anderson (Eds.), Handbook of distance education (pp. 331-348). Lawrence Erlbaum Associates.

Byrd, J. C. (2016). Understanding the online doctoral learning experience: Factors that contribute to students' sense of community. Journal of Educators Online, 13(2), 102-135. https://www.thejeo.com/archive/2016_13_2/byrd

Cleveland-Innes, M., \& Campbell, P. (2012). Emotional presence, learning, and the online learning environment. The International Review of Research in Open and Distributed Learning, 13(4), 269-292. https://doi.org/10.19173/irrodl. v13i4.1234

Cook, C. W., \& Sonnenberg, C. (2014). Technology and online education: Models for change. Contemporary Issues in Education Research, 7(3), 171-188. https://doi.org/10.19030/ cier.v7i3.8638

Council of Graduate Schools. (2017). The crucial issue of doctoral non-completion. Author. https://cgsnet.org/cgs-occasionalpaper-series/university-georgia/chapter-1

Cross, T. M. (2014). The gritty: Grit and non-traditional doctoral student success. Journal of Educators Online, 11(3), 1-30. https://www.thejeo.com/archive/2014_11_3/cross

Ehrenberg, R. G., Zuckerman, H., Groen, J. A., \& Brucker, S. M. (2009, October 12). How to help graduate students reach their destination. The Chronicle of Higher Education, 56(08). https://www.chronicle.com/article/how-to-help-graduatestudents-reach-their-destination/

Fiore, T. D., Heitner, K. L., \& Shaw, M. (2019). Academic advising and online doctoral student persistence from coursework to independent research. Online Journal of Distance Learning Administration, 22(3), 1-15. https://www.westga. edu/ distance/ojdla/fall223/fiore_heitner_shaw223.html
Friedman, J \& Moody, J. (2021, January 26). Discover 14 Current Online Learning Trends. U.S. News \& World Report. https:// www.usnews.com/higher-education/online-education/ articles/2018-01-11/study-more-students-are-enrolling-inonline-courses

Gardner, S. K. (2010). Contrasting the socialization experiences of doctoral students in high- and low-completing departments: A qualitative analysis of disciplinary contexts at one institution. The Journal of Higher Education, 81(1), 61-81. https://doi.org/ 10.1080/00221546.2010.11778970

Garrison, D. R. (2009). Communities of inquiry in online learning: Social, teaching and cognitive presence. In C. Howard et al. (Eds.), Encyclopedia of distance and online learning (2nd ed., pp. 352-355). IGI Global.

Garrison, D. R. (2012). Article review-social presence within the community of inquiry framework. International Review of Research in Open and Distributed Learning, 13(1), 250-252. https://doi.org/10.19173/irrodl.v13i1.1184

Garrison, D. R., Anderson, T., \& Archer, W. (2000). Critical inquiry in a text-based environment: Computer conferencing in higher education. The Internet and Higher Education, 2(2-3), 87-105. https://doi.org/10.1016/S1096-7516(00)00016-6

Garrison, D. R., Anderson, T., \& Archer, W. (2001). Critical thinking, cognitive presence, and computer conferencing in distance education. American Journal of Distance Education, 15(1), 7-23. https://doi.org/10.1080/08923640109527071

Gervais, J. (2016). The operational definition of competency-based education. The Journal of Competency-Based Education, 1(2), 98-106. https://doi.org/10.1002/cbe2.1011

Gyll, S., \& Ragland, S. (2018). Improving the validity of objective assessment in higher education: Steps for building a bestin-class competency-based assessment program. Journal of Competency-based Education, 3(1), e01058. https://doi. org/10.1002/cbe2.1058

Holton, E. F., Swanson, R. A., \& Naquin, S. S. (2001). Andragogy in practice: Clarifying the andragogical model of adult learning. Performance Improvement Quarterly, 14(1), 118-143. https:// doi.org/10.1111/j.1937-8327.2001.tb00204.x

Jiang, M., Ballenger, J., \& Holt, W. (2019). Educational leadership doctoral students' perceptions of the effectiveness of instructional strategies and course design in a fully online graduate statistics course. Online Learning, 23(4), 296-312. https://dx.doi.org/10.24059/olj.v23i4.1568

Jiang, M. \& Koo, K. (2020). Emotional presence in building an online learning community among non-traditional graduate students. Online Learning, 24(2), 93-111. https://doi. org/10.24059/olj.v24i4.2307 
Jiang, M., \& Koo, K. (2020, June 23). Emotional presence in building an online learning community among non-traditional higher education students. Paper presented at Online Learning Consortium Innovate Virtual Conference.

Johnson, E. M., Green, K. E., \& Kluever, R. C. (2000). Psychometric characteristics of the revised procrastination inventory. Research in Higher Education, 41(2), 269-279. https://doi.org/10.1023/A:1007051423054

Johnstone, S. M., \& Soares, L. (2014). Principles for developing competency-based education programs. Change: The Magazine of Higher Learning, 46(2), 12-19. https://doi.org/10.1 080/00091383.2014.896705

Joyner, R. L., Rouse, W. A., \& Glatthorn, A. A. (2018). Writing the winning thesis or dissertation: A step by step Guide. Corwin.

Knowles, M. S. (1970). The modern practice of adult education: Andragogy vs. pedagogy. Association Press/Follett.

Knowles, M. S. (1985). Andragogy in action: Applying modern principles of adult learning. Jossey-Bass.

Larwin, K., \& Larwin, D. (2011) A meta-analysis examining the impact of computer-assisted instruction on postsecondary statistics education. Journal of Research on Technology in Education, 43(3), 253-278. https://doi.org/10.1080/15391523. 2011.10782572

Le, C., Wolfe, R., \& Steinberg, A. (2014, September 15). The past and the promise: Today's competency education movement. Students at the Center. https://studentsatthecenterhub.org/ resource/the-past-and-the-promise-todays-competencyeducation-movement/

Lipman, M. (2003). Thinking in education (2nd ed.). Cambridge University Press.

Lovitts, B. (2008). The transition to independent research: Who makes it, who doesn't and why. The Journal of Higher Education, 79(3), 296-325. https://doi.org/10.1080/00221546. 2008.11772100

Lu, F., \& Lemonde, M. (2013). A comparison of online versus face-to-face teaching delivery in statistics instruction for undergraduate health science students. Advances in Health Sciences Education, 18, 963-973. https://doi.org/10.1007/ s10459-012-9435-3

McDonald, P., Straker, H., Schlumpf, K., \& Plack, M. (2014). Learning partnership: Students and faculty learning together to facilitate reflection and higher order thinking in a blended course. Online Learning, 18, 73-93. http://dx.doi. org/10.24059/olj.v18i4.516

Mcgee, P., Windes, D., \& Torres, M. (2017). Experienced online instructors: Beliefs and preferred supports regarding online teaching. Journal of Computing in Higher Education, 29, 331-352. https://doi.org/10.1007/s12528-017-9140-6
Nodine, T. R. (2016). How did we get there? A brief history of competency-based higher education in the United States. The Journal of Competency-based Education, 1(1), 5-11. http://doi. org/10.1002/cbe2.1004

Peters, G. B., Gurley, K., Fifolt, M., \& Collins L. (2015). Maintaining a strong collaborative community in the early dissertationwriting process: Reflections on program interventions. The Journal of Continuing Higher Education, 63(1), 44-50. https:// doi.org/10.1080/07377363.2015.996848

Priest, N., Rudenstine, A., \& Weisstein, E. (2012). Making mastery work: A close-up view of competency education. Nellie May Education Foundation.

Reio Jr., T. G., \& Crim, S. J. (2013). Social presence and student satisfaction as predictors of online enrollment intent. American Journal of Distance Education, 27(2), 122-133. https://doi.org/ 10.1080/08923647.2013.775801

Rivenbark, W. C., \& Jacobson, W. S. (2014). Three principles of competency-based learning: Mission, mission, mission. Journal of Public Affairs Education, 20(2), 181-192. https://doi. org/10.1080/15236803.2014.12001781

Seaman, J. E., Allen, E., \& Seaman J. (2018). Great increase: Tracking distance education in the United States. Babson Survey Research Group. https://onlinelearningsurvey.com/ reports/gradeincrease.pdf

Shea, P., \& Bidjerano, T. (2009). Community of inquiry as a theoretical framework to foster "epistemic engagement" and "cognitive presence" in online education. Computers \& Education, 52(3), 543-553. https://doi.org/10.1016/j. compedu.2008.10.007

Smith, S. U., Hayes, S., \& Shea, P (2017). A critical review of the use of Wenger's Community of Practice (CoP) theoretical framework in online and blended learning research, 2000-2014. Online Learning, 21(1), 209-237. https://dx.doi. org/10.24059/olj.v2111.963

Spady, W. G. (1977). Competency-based education: A bandwagon in search of a definition. Educational Researcher, 6(1), 9-14. https://www.jstor.org/stable/1175451

Stenbom, S., Hrastinski, S., \& Cleveland-Innes, M. (2016). Emotional presence in a relationship of inquiry: The case of one-to-one online math coaching. Online Learning, 20(1), 1-16. https://dx.doi.org/10.24059/olj.v20i1.563

Stenbom, S., Jansson, M., \& Hulkko, A. (2016). Revising the community of inquiry framework for the analysis of one-toone online learning relationships. International Review of Research in Open and Distributed Learning, 17(3), 36-53. https://doi.org/10.19173/irrodl.v17i3.2068 
Terrell, S. R., Lohle, M. F., \& Kennedy, D. (2016). Studentidentified requirements for persistence in a limited-residency information systems PhD program. Online Journal of Applied Knowledge Management, 4(1), 150-164. http:// www.iiakm.org/ojakm/articles/2016/volume4_1/OJAKM_ Volume4_1pp150-164.pdf

Texas Higher Education Coordinating Board. (2018). 2018 Texas public higher education almanac: A profile of state and institutional performance and characteristics. http://www. thecb.state.tx.us/reports/PDF/10900.PDF?CFID=86738635\& CFTOKEN $=96628409$

Tsai, I.-C., Kim, B., Liu, P.-J., Goggins, S. P., Kumalasari, C., \& Laffey, J. M. (2008). Building a model explaining the social nature of online learning. Educational Technology \& Society, 11(3), 198-215. https://www.jstor.org/stable/ jeductechsoci.11.3.198

Williams, A. S. (2010). Statistics anxiety and instructor immediacy. Journal of Statistics Education, 18(2). https://doi.org/10.1080/1 0691898.2010 .11889495

Williams, P. E., Wall, N., \& Fish, W. W. (2019). Mid-career adult learners in an online doctoral program and the drivers of their academic self-regulation: The importance of social support and parent education level. International Review of Research in Open and Distributed Learning, 20(1), 63-78.

Williams, S. (2017). The managed heart: Adult learners and emotional presence online. The Journal of Continuing Higher Education, 65(2), 124-131. https://doi.org/10.1080/07377363. 2017.1320204

Yang, D. (2017). Instructional strategies and course design for teaching statistics online: perspectives from online students. International Journal of STEM Education, 4(1). https://doi. org/10.1186/s40594-017-0096-x 